\title{
Bulanık Mantık Yaklaşımının Eğitim Çalışmalarında Kullanılmasının Alan Yazın Işı̆̆ında Değerlendirilmesi
}

Fuzzy Logic Approach and its Evaluation in Using Educational Studies in the Light of Literature

Elif Bahadır

Matematik ve Fen Bilimleri Eğitimi Bölümü, Yıldız Teknik Üniversitesi, İstanbul, Türkiye

\begin{abstract}
Özet
Günümüzde karar verme problemlerinin çoğu tam ve kesin olmayan bilgilerin kullanılmasını gerektirmesine rağmen, birçok karar verme ve problem çözme aracı nicel verilerin kullanılması ile çc̈züme gitmektedir. Bulanık küme teorisi karar verme sürecinde kesin olmayan, yaklaşık bilgilerin kullanılmasına imkân tanımakta ve belirsiz birçok problemin matematiksel olarak formüle edilmesini sağlamaktadır. Bu çalışmada bulanık mantık yaklaşımından bahsedilmiş, bulanık mantığın avantajları ve dezavantajlarına değinilmiş, bulanık mantık ile sosyal alanlar ve özelde eğitim alanında yapılmış çalışmalar incelenmiştir. "Bulanık mantık eğitim araştırmalarında nasıl ve niçin kullanılmaktadır?" sorusunun cevabı irdelenmiştir. Çalışmaların içeriklerine değinilerek bu alandaki çalışmalar hakkında araştırmacılara fikir vermek amaçlanmıştır. Çalışmalarda yoğunlukla başarı sınıflaması ve personel seçiminin yapıldığı araştırmalara rastlanmıştı. Çalışmaların sonuçları, akademik başarının belirlenmesinde sadece belirli nicel değerlere odaklanmak yerine, çoklu kriterlere yönelmenin daha esnek ve gerçekçi bir sıralamayı veya sınıflamayı beraberinde getirdiğini ve bulanık mantıkla yapılan değerlendirmenin diğer klasik değerlendirme yöntemlerine göre daha başarılı sonuçlar verdiğini göstermektedir.

Anahtar Kelimeler: Bulanık mantık, Eğitim, Akademik Başarı, Sınıflama.
\end{abstract}

\begin{abstract}
Nowadays, although most of the decision-making problems require the use of indefinite information, many decision-making and problem-solving tools are solved by the use of quantitative data. The fuzzy set theory allows the use of approximate, inexact information in the decision making process, and ensures that many indefinite problems are mathematically formulated. In this study, the fuzzy logic approach was mentioned, the advantages and disadvantages of fuzzy logic were discussed, fuzzy logic and social fields and studies especially in the field of education were examined. The answer to the question of "How and why is fuzzy logic used in educational researches?" has been examined. It is aimed to give an idea to the researchers about the studies in this area by referring to the contents of the studies. Studies have been found to have concentrated on researching success classification and personnel selection. The results of the studies show that instead of focusing only on certain quantitative values in the determination of academic success, turning onto the multiple criteria brings along more flexible and realistic ranking or classification with it and the evaluation done by fuzzy logic gives more successful results than the other classical evaluation methods.

Key Words: Fuzzy logic, Education, Academic Success, Classification.
\end{abstract}

CONTACT : Elif Bahadır, elifbahadir@gmail.com

Geliş Tarihi \& First Received : 23.02.2017

Kabul Tarihi \& Accepted $\quad$ : 15.04.2017 


\section{Giriş}

Bilimsel çalışmaların çoğunda Aristo Mantığı temel alınmaktadır. Buna göre olaylar, doğru ya da yanlış, siyah ya da beyaz kavramlarında olduğu gibi iki seçenekli olarak incelenmektedir. Ancak, gerçek hayata yönelik olgular her zaman bu kadar yalın değildir. Günlük hayata ilişkin olaylar, alınan kararlar insan zihninde karmaşık süreçlerden geçirilmekte ve beraberinde bir takım belirsizlikleri içermektedir. Bilinen belirsizliklerin çoğu aslında rastgele karakterde olmadığı gibi problemlerin çözümüyle ilgili bilgi kaynakları da çeşitlilik içerebilmektedir. $\mathrm{Bu}$ aşamada, Bulanık Mantık (Fuzzy Logic) ve Bulanık Küme Teorisi (Fuzzy Set Theory) birlikte ideal çözüm olarak karşımıza çıkmaktadır. Çeşitli nedenler ve bilgi eksikliğinden dolayı ortaya çıkan karmaşıklık ve belirsizliler Bulanık Mantıkla kolaylıkla modellenebilmektedir. (Uysal, 2010: 1042)

Bulanıklılık bir nevi derecelendirmeyle alakalıdır. Varlığın ve nesnelerin özelliklerinin iki değer $(0 ; 1)$ ile ifade etmenin yeterli olmayacağını ve böyle bir kademelendirmenin yetersiz olduğunu öngörür. Gerçek dünyanın genel görünümü ise 0 ile 1 arasında bulunan yüzlerce aralıktan, benzerlikten ve karşıtlıktan ibarettir. Yani dünya, kesikli-kesintili değildir, süreklikesintisizdir. Bulanık mantığın en geçerli olduğu iki durumdan ilki, incelenen olayın çok karmaşık olması ve bununla ilgili yeterli bilginin bulunmaması durumunda kişilerin görüş ve değer yargılarına yer verilmesi, ikincisi ise insan kavrayış ve yargısına gerek duyan hallerdir. İnsan düşüncesinde sayısal olmasa bile belirsizlik, yararlı bir bilgi kaynağıdır. İşte bu tür bilgi kaynaklarının, olayların incelenmesinde özgün bir biçimde kullanılmasına bulanık mantık ilkeleri yardımcı olmaktadır. Bulanık kümeler klasik kümelerden oldukça farklıdır. Mesela Klasik kümelerdeki keskin ve ani geçişlerin aksine bulanık kümelerdeki geçiş yumuşak ve sürekli bir şekilde olmaktadır (Kazançoğlu ve Aksoy, 2011: 84).

Klasik kümelerde bir öğenin kümeye ait olması için üyelik derecesinin mutlaka 1'e eşit olması gerekirken, bulanık kümede nerede ise bütün öğelerin değişik derecelerle kümeye ait olmaları mümkündür. Ayrıca bir bulanık kümesi aynı değişken özelliğine sahip olmak üzere başka bir kümenin de öğesi olabilir. Bulanık mantı̆̆ın sibernetikte ve yapay zekâ çalışmalarında, dolayısıyla bilgisayar alanında ve buradan da hareketle sanal gerçekliğin yapay zekâ çalışmalarındaki etkileri önemsenmeyecek gibi değildir.

Yapay zeka çalışmalarının bir ürünü olan ve çok değerli mantığı kullanımımıza sunan bulanık mantık bugün pek çok alanda önemli şekilde kullanılmaktadır. Bunların başlıcaları; kontrol algoritmaları, tıbbi tahliller, karar verme, ekonomi, mühendislik, çevre, yöneylem araştırması, örnek tanımlama, psikoloji, güvenirlik, güvenlik, atık su, su araştırmaları v.s.'dır. Bulanık mantığın ilk uygulamaları genellikle endüstriyel alanlardadır (Terzi, 2004: 28). Bulanık mantık uygulamalarına yer verilen pek çok mühendislik alanını örnek vermek mümkündür. Sunter, Altun ve Sunter (2015), Bukata ve Li, (2012), Singh ve Arya, (2014), Onat, Gumus, Kucukvar ve Tatari, (2016), Altaş ve Sharaf, (1992), Liu, (1997), Li, Lai ve David, (1999) güç elektriği konusunda, Kosko,(1992), Arafehatall, (1999) makine ve dinamik sistemler, Akiyama ve Tsuboi, (1996), Lo ve Lam, (1997), Henn, (1997), ulaştırma ve trafik mühendisliği alanında çalışmalar yapmışlardır.

Bulanık mantık sayesinde etkili karar ve sınıflama sadece mühendislik alanlarında değil farklı sosyolojik alanlarda da kullanılmaktadır. Bilim insanları artık sosyolojik olguları kesin ve net kalıplara sığdırıp açıklamaktansa daha çok yaklaşık değerlerle toplumlar üzerine varsayımlarda bulunabilmektedirler. Aynı şekilde sosyolojik anketlerde kullanılan dil de bulanık mantık ilkeleri ve dilin bulanık özelliğinden yararlanılarak daha gerçekçi ve güvenilir araştırmaları sonuç verebilmektedir. Bu bağlamda bulanık mantığın dil, felsefe, din, sosyoloji, eğitim ve hukuk, gibi alanlarla ilişkisinin önemli araştırma konuları olduğunu söylenebilir.

Mesela sosyoloji alanında toplumların birbirleriyle olan bağları incelendiğinde aradaki sınırları daha saydam hale getirebilecek yorumlara bulanık mantık çalışmaları ile 
ulaşılabilmektedir. Aynı şekilde hukukta verilen yargılamalarda bulanık mantık düşüncesi ikilemlerde kalan ve çıkmazlara sürüklenen dava süreçlerinde belirleyici rol oynayabilmektedir. Benzer şekilde araştırmamızın odak noktası olan eğitim alanında da öğrencilere ve eğitim çalışanlarına güçlü karar verme mekanizmaları kurmalarında yardımcı olmaktadır. Akademik başarının dolaylı ve direk olarak birçok faktörle ilişkili olduğu bilinmektedir. Akademik başarının irdelendiği ve bu başarıyı etkileyen bilişsel-duyuşsal bileşenlerin belirlenmesi yönünde çeşitli çabalar mevcuttur.

Akademik başarı değerlendirmede geleneksel değerlendirme sistemleri ekseriyetle kullanılmaktadır. Geleneksel değerlendirme sistemleri objektif ve sübjektif değerlendirme ölçüleri kullanarak yapılandırılan sistemin temsilcileridir. Ölçülebilir özellikler genellikle kesin değerler tarafından gösterilir. Liderlik, temsil ve problem çözme yetenekleri gibi subjektif ölçüler ise daha az ölçülebilirdir. Akademik dünyanın eğitim hizmeti ve diğer nitel araştırmalarda olduğu gibi değerlendirme kriteri subjektiftir. Değerlendirme sistemine bağl1 olarak, bulanık mantık uygun olmaktadır (Akandere, Özyalvaç ve Duman,2010: 3).

Etkili karar vermenin ve sınıflamanın en önemli olduğu alanlardan biri şüphesiz eğitim alanıdır. Bulanık mantık yaklaşımının sınıflama, karar verme ve çeşitli duyuşsal öğelerin değerlendirmesinin yapılabilmesi için klasik değerlendirmelere alternatif olması ve eğitim alanında yapılacak çalışmalarda etkin ve yaygın bir şekilde kullanılması umulmaktadır.

\section{2. Çalışmanın Amacı}

Bireylerin akademik başarılarının pek çok faktörle ilişkisi olduğu düşünüldüğünde etkili bir değerlendirmenin önemi de ortaya çıkmaktadır. Literatürde akademik başarıyı etkileyen pek çok bileşenle ilgili çeşitli çalışmalar yapılmıştır. Bu bileşenler ve çalışmalardan bazıları şu şekildedir. Akademik başarının, motivasyon, (Cox, 1990); tutum (Peker ve Mirasyedioğlu 2003; Şen ve Koca 2005; Dede,2010); eleştirel düşünme (Chen ve Cheng (2006); öğrenme yaklaşımları (Rollnick, 2008); uyum düzeyi (Saral, 1993); cinsiyet (Kılıç ve Karadeniz, 2004); öğrenme stili, ebeveyn desteği (Diaz, 1989; Zvolensky ve ark, 2006); okul kültürü (Demirtaş, 2010) gibi pek çok bileşene bağlı olduğu araştırmalarla ortaya koyulmaktadır.

Akademik başarı belirlemede öğrencilerin bilişsel başarı durumlarını anlamak için kullanılan teknikler; yazılı sınav, test ve sözlü sınavdır. Duyuşsal bileşenleri belirlemek için ise çoğunlukla ölçekler kullanılmaktadır. Dolayısıyla, belirli kriter ve ağırlıkları temel almamış olan bu yöntemler ölçme ve değerlendirme sürecinde sübjektifliğe ve buna bağlı olarak yanlış değerlendirmelerin yapılmasına neden olabilmektedir. Yapay zeka ve bulanık mantık uygulamaları sayesinde daha geniş perspektiften ve esnek bir yorum getirmek modelin doğası gereği mümkün olmaktadır.

Akademik başarıyı etkileyen bütün bu bileşenler düşünüldüğünde başarı ölçütlerinin hiyerarşik yapısı nedeni ile bulanık mantık problemi olarak değerlendirilebilir. Eğitim çalışmalarında kullanılmakta olan klasik yöntemlere alternatif olan bulanık mantık çalışmalarının nasıl kullanıldığı, avantajları ve dezavantajlarından bahsedilmiştir. Akademik başarıyı etkileyen farklı bileşenlerin bulanık mantık yöntemi ile değerlendirildiği araştırmalar bu çalışmada sunulmuştur. Bu sayede bulanık mantığın eğitim çalışmalarında yaygın kullanımına katkı sunmak amaçlanmıştır.

\section{3. Çalışmanın Problem Durumu}

$\mathrm{Bu}$ çalışma, akademik başarının değerlendirilmesi için; kullanımı kolay, öğrencilere ait verileri ortak bir bazda değerlendirebilen, esnek, sözel değişkenlerle ifade edilen, ölçütleri kolaylıkla sayısallaştırabilen bir model olan bulanık mantık yaklaşımını esas alan araştırmaların irdelendiği bir çalışmadır. Bulanık mantık yaklaşımı sosyal çalışmalarda özellikle eğitim çalışmalarında hangi amaçlarla, hangi aşamalarda ve nasıl uygulandığına dair bütüncül bir fikir oluşturması hedeflenmiştir. Bütün dünyada yükselen bir kabul oranı ile hemen hemen tüm 
alanlarda kullanılan bulanık mantık yaklaşımının eğitim çalışmalarında kullanılması ile ilgili "Bulanık mantık eğitim araştırmalarında nasıl ve niçin kullanılmaktadır?" sorusunun cevabı bu çalışmada irdelenmiştir.

\section{Yöntem}

Yaşamın her alanında özellikle bilişim teknolojisinde vazgeçilmez bir hal alan bulanık mantık ile eğitim alanında yapılan çalışmaların derlenmesi sayesinde eğitim çalışmalarında güçlü bir karar mekanizmasının sağlanmasına yardımcı olacağı düşünülen bu çalışma literatür tarama modelli bir araştırmadır.

Bu çalışmada bulanık mantık yaklaşımından bahsedilmiş, bulanık mantığın avantajları ve dezavantajlarına değinilmiş, bulanık mantık ile sosyal alanlar ve özelde eğitim alanında 20002016 yılları arasında yapılan ve tam metnine ulaşılabilen çalışmalara yer verilmiştir. Çalışmaların içeriklerine değinilerek bu alandaki çalışmalar hakkında araştırmacılara fikir vermek amaçlanmıştır.

\subsection{Bulanık Mantık ve Bulanık Kümeler}

Bulanıklık, aktivitelerin veya gözlemlerin küme sınırlarının iyi tanımlanmadığı, puslu olduğu durumları ifade etmektedir. Bulanık mantık, bulanık küme teorisine dayanır. Bulanık küme teorisi aslında daha genel bir matematiksel küme yaklaşımı olup, nesnelerin belirli üyelik dereceleri ile kümeye dahil olmasını sağlamaktadır (Terzi, 2004). Bilim ve teknolojideki gelişmeler günümüzün modern toplumunu çok karmaşık bir sistem haline getirmiştir. Mühendislikte ve diğer bilim dallarında sistemler, kesin matematiksel yöntemler kullanılarak modellenirken, karar süreçlerinin belirsizliği nedeniyle problemlerin çözümünde yeni bir teknik ve çözüm arayışına gidildi. Bulanık mantık, klasik mantıktaki gibi kesin hatlarla birbirinden ayrılmış bölgeler yerine, bizim tarafımızdan tanımlanan fonksiyonlarla birbirinin içine geçmiş çok sayıdaki bölgeleri kullanır. Bulanık küme teorisinin mantığa uygulanması ile yani bulanık mantık ile asıl hedeflenen, insan gibi düşünebilen, karar verebilen, inisiyatif kullanabilen, duruma göre seçim yapabilen kontrol sistemleri oluşturmaktır. (Temurtaş, 2000). Yüzyılımız içinde bilim ve matematik dalındaki değişmeler, belirsizlik kavramına bakış açısını değiştirmiştir. Geleneksel görüşe göre, belirsizlik bilim içinde istenmeyen bir durumdur ve bütün imkânlar kullanılarak yok edilmelidir. Bu düşünce bilim adamlarını bu yönde araştırmalar yapmaya itmiştir. İnsanoğlunun mantık süreçlerinin daha etkin ve hızlı çalışmasının nedeni bulanık bir yapıya sahip olmasıdır. Biraz kısa, uzun, ılık, hafif gibi sınırları tam olarak belirli olmayan kavramlar, diğer insanlarla anlaşmak için başarılı bir şekilde kullanılmasının yanında; mantık süreçlerinin bilgisayarlara göre başarılı bir şekilde yürümesini de sağlamaktadır. Bulanık mantık; kısmi üyeliğe izin veren bir teoridir. Yani bir kümenin üyesi olma ve olmama durumları arasında, kademe-kademe geçişe izin verir. Verilen bir elemanın bir kümede kısmi üyeliğinin başlaması demek aynı zamanda bu elemanın, bu kümenin üyesi olmama durumunun da kısmen başlaması demektir. Çünkü bulanık küme teorisi, hem tam üyeliğe hem de hiç üye olmamaya izin verir. İşte bundan dolayı bulanık küme teorisi, klasik küme teorisinin genelleştirilmiş bir halidir denebilir (Yuan, 1994).

Bulanık Küme Kuramı İsminin insanlarda çağrıştırdığının aksine bulanık mantık belirsiz ifadelerle yapılan, belirsiz işlemler değildir. Gelişmiş bir olasılık hesaplama yöntemi de değildir. Aslında, modelleme aşamasında değişkenler ve kuralların esnek belirlenmesidir. Bu esneklik asla rastgelelik ya da belirsizlik içermez. Nasıl bir lastik içinde bulunduğu duruma göre şeklini değiştirirken bütünlüğünü ve yapısını koruyabilirse, bir bulanık mantık modeli de değişen koşullara değişen cevaplar verirken özündeki yapıyı muhafaza eder (Temurtaş, 2000).

Bulanık kümelerle belirlenen kurallarla sistem girdileri, istenen çıktılara dönüştürülür. Girdiler sırayla, bulanıklaştırma, kontrol ve durulaştırma aşamalarından geçer. Bulanık kümeler, kurallar ve üç aşamayı tek yapı halinde gösterirsek aşağıdaki tabloyu kullanabiliriz. 


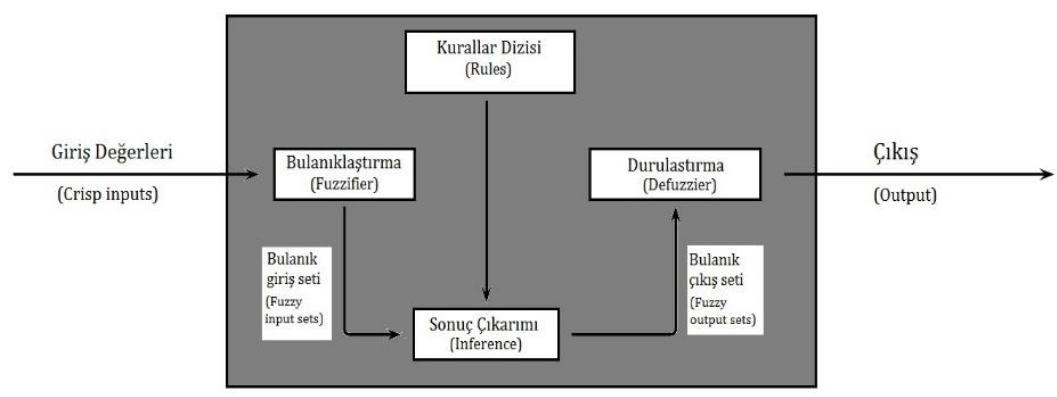

Şekil 1. Bulanık mantığın işleyiş şeması

Tanımlanacak kurallar, giriş değerlerine göre vereceği karar mekanizmasını oluşturur. Giriş değerlerine verilen derecelerle de üyelik fonksiyonları hazırlanır. Üyelik fonksiyonları, bir elemanın, bir alt kümeye olan yakınlığını $[0,1]$ arasında ölçümlemeye yarar. Eldeki bilgileri ve tanımlanan kuralları kullanarak aralarında bağlantı kurma ve bulanık değerlere sahip kümeler oluşturma sürecine bulanıklaştırma denir. Bu aşama sonrasında istenen sonuç bilgisinin bulanık hali ortaya çıar.

Üyelik fonksiyonlarının sunduğu en iyi noktaya karşıllk gelen değer problemin çözümüdür. Aşamaları tekrar gözden geçirirsek, bulanık sistem, dışarıdan aldığı değişkenlerle karar verme mekanizmasını sağlayan üyelik fonksiyonlarını hazırlayarak ve kurallar süzgecinden geçirerek en uygun çıktıyı almayı sağlamaktadır. Diğer girdiler de kümelere olan yakınlıklarına göre $[0,1]$ arasında değerler alır (Aydın,2015).

\subsubsection{Bulanık Mantığın Avantajları}

Bulanık mantığın avantajı, sınıflandırılmış olan nitelikli bilginin kullanılabilir olmasında yatmaktadır. Bulanık mantıklı denetim uygulamalarının diğer yöntemlere göre avantajları şöyle siralanabilir (Bellman, 1970, Aktaran: Sattarov 2008).

a) Detaylı bir matematiksel model gerektirmezler,

b) Pek çok giriş-çıkış değişkenleri eş zamanlı olarak ele alınabilir,

c) Bulanık denetimdeki tüm kurallar eş zamanlı olarak uygulanır ve sonuçlandırılır, uyuşmayan kurallar biçimsel olarak uydurulabilir,

d) Giriş-çıkış değişkenlerinin tüm birleşimleri için çıkış belirleme zorunluluğu yoktur. Değişkenlerin dikkatli bir seçimi kuralların sayısını önemli ölçüde indirgeyecektir,

e) Bulanık denetleyici içerisine yerleştirilen denetim kuralları sistem girişlerinin belirli birleşimlerinde istenilen çıkış elde edilmezse diğer girişlere dokunulmadan denetim işlemini gerçekleştiren aktif kurallar yeniden düzenlenebilir. Bulanık denetleyiciye kurallar rahatlıkla eklenebilir veya istenen belirli bir özellikteki denetim kurallarının özelliği rahatlıkla sistem davranışını bozmayacak şekilde etkin hale getirilebilir,

f) Bulanık mantık denetleyicilerle klasik mantık denetleyicileri birbirine bağlamak suretiyle denetim performansını artırmak mümkündür.

g) Karmaşık sistemlerde istenen kalite, nitelik ve hıza göre birden fazla bulanık denetleyici kullanılabilir,

h) Gerçek zaman uygulamalarının denetim altına alınabildiği sistemlerde yeterli zaman sağlanabiliyorsa donanımdan ziyade yazılımın verdiği esneklikten dolayı bulanık denetim kullanılmaktadır,

i) Farklı sistemlerde bulanık denetleyici adaptasyonu kolay bir şekilde yapılabilmektedir. 


\subsubsection{Bulanık Mantığın Dezavantajları}

Bulanık mantık kullanımının dezavantajları aşağıdaki gibi sıralanabilir (Bellman, 1970; Aktaran: Sattarov 2008). a) Uygulamada kullanılan kuralların oluşturulması uzmana bağlıdır. Kullanılan kural tabanı karar mekanizmasının temelinde yer alması nedeniyle uzman tecrübelerine dayanması gerekmektedir.

b)Kullanılacak üyelik fonksiyonlarının bulunması için kullanılabilecek genel bir kural bulunmamaktadır. Belirleme işlemi deneme yanılma yolu ile bulunmasından dolayı uzun zaman alabilmektedir.

c)Bulanık Mantık Sistemleri kendi başlarına öğrenme yeteneğine sahip değillerdir. Bu özelliği sağlamak için sinir ağları kullanımı, endüktif öğrenme gibi yöntemler kullanılmaktadır. $\mathrm{Bu}$ şartlara uymayan durumlar için mevcut kuralların kullanılması mümkün değildir.

\section{Bulanık Mantıkla Sosyal Alanlar ve Eğitim Alanında Yapılan Çalışmalar}

Sosyal alanlarda bulanık mantıkla yapılan çalışmalar mühendislik alanlarına nazaran daha azdır. Sosyal alanlardaki bulanık mantık uygulamalarına en önemli katkıy 1980lerin sonunda Smithson (1987) fuzzysetstheory ile yapmıştır. Takiben, Fourali (1997), ChangandYeh (2002) $\mathrm{Hu}(2009)$ önemli çalışmalar yapmışlardır.

Bendjebar, Lafifi ve Seridi, (2016), E-öğrenme sistemlerinde, uygun profili öğretmenlerin işlevlerinin modellenmesi ve değerlendirilmesi için bulanık mantık ile yeni bir yaklaşım önermektedirler. E öğrenme sisteminde önerilen öğretmen modelinin bileşeni, her bir öğretmen hakkında gerekli bilgileri temsil etmekle yükümlü olan profillerden oluşmaktadır. Öğretmenin ders profilini tanımlamak için bulanık mantık tekniği kullanılmıştır. Çalışmada kullanılan yeni yaklaşım, Cezayir Üniversitesi'nden öğretmenler tarafından test edilmiştir. İlk sonuçlar yeterli bulunmuş Bulanık mantık tekniğinin çok kullanışlı olduğunu ve öğretmenin becerilerine göre ders verme sürecinin adaptasyonunu etkili bir şekilde tahmin ettiği sonucuna ulaşmışlardır.

Voskoglou, (2013) çalışmasında öğrenci gruplarının bilgi ve becerilerini değerlendirmek için bulanık bir model geliştirmişlerdir. Bu modelde, öğrencilerin değerlendirme altındaki özellikleri (konu hakkında bilgi, problem çözme becerileri ve analog akıl yürütme becerileri), performanslarını karakterize eden bir dizi dilsel etiketin bulanık alt kümeleri olarak temsil edilmesi ve tüm öğrenci profillerinin olasılıklarının hesaplanmasına odaklanılmıştır. Bu şekilde, öğrencilerin grup performansı hakkında ayrıntılı nicel / nitel bir çalışma ile sonuçlar elde etmişlerdir.

Alsam ve Khan (2013), bu çalışma, Pakistan'da öğrencilere en uygun fakülte seçmelerinde yardımcı olacak, kural tabanlı bir Karar Destek Sisteminin tasarlanması ve geliştirilmesini sunmaktadır. Çalışmada uygulanan yaklaşımın temel fikri, zekâ, anlama, matematiksel kavramlar ve geçmiş akademik kaydı dikkate alarak öğrenci yeteneklerini test etmek ve ölçmek için bir model tasarlamaktır. Modelden elde edilen modül sonuçlarını kural tabanlı bir uygulamayla Gomal Üniversitesi'ndeki mevcut fakülte / bölümlerle öğrencilerin uyumluluğunu belirlemek için karar verme tabanlı karar destek sistemi oluşturmuşlardır.

Sobecki (2012) çalışmasında öğrencilere kursların önerilmesine yönelik problemlerin bulanık mantık algoritmalarından yararlanarak duruma ilişkin optimizasyon probleminin çözümünde etkili olduğunu kanıtlamıştır. Bu algoritmaları uygulamak için, her bir algoritmaya uygun sorunun özel temsiline ihtiyaç duyulmaktadır.

Kazancoglu ve Aksoy (2011) çalışmalarında, e-öğrenme tasarım gereksinimlerini belirlemek ve en uygun öğrenmeyi seçmek için servis sağlayıcılarını bulanık mantık ile belirlemişlerdir. Bu araştırmada, bulanık mantık temelli Kalite Fonksiyonu Dağıtımı (QFD) uygulanmış, araştırmada seçilen bir grup uzmana ait verileri toplamak için bir anket yapılmıştır. Anketten elde edilen dönüştürme bulanık verilerini Crisp'e dönüştürerek elde edilen skorlar 
(CFCS) tekniği sayesinde berraklaştırılmıştır. Daha sonra, e-öğrenmenin kritik başarı faktörleri belirlenip servis sağlayıcılar belirlenmiştir. Sonuç olarak araştırmada bulanık mantık tabanlı QFD tekniğini e-öğrenme tasarım gereksinimleri için kullanmışlardır.

Dağdeviren (2007)'de yaptığı araştırmasında bulanık küme teorisi kullanan bir algoritma geliştirmiştir. Geliştirilen metotta kişilik, liderlik, deneyim gibi sübjektif kriterler ile genel yetenek, iş bilgisi, analitik düşünebilme becerisi gibi objektif kriterler kullanılmıştır. Önerilen algoritma bir işletmede terfi edilecek bir pozisyon için ön şartları sağlamış olan üç adayın değerlendirilmesi ve terfi edecek adayın belirlenmesi amacıyla uygulanmıştır. Çalışmada belirsizlik içeren bir süreç olan personel seçim sürecinin, bulanık sayılar ve dilsel değişkenler kullanılarak aşılabileceği sonucuna ulaşılmıştır.

Özgörmüş, Mutlu ve Güner (2005) "Bulanık AHP İle Personel Seçimi” isimli çalışmasında gıda sektöründe faaliyet gösteren bir işletmenin mühendis seçme problemi ele alınmıştır. İşletmenin insan kaynakları birimi tarafından yapılan iş analizleri sonucunda hazırlanan iş tanımlarından yola çıkılarak işin gerektirdiği özellikler belirlenip bir algoritma oluşturulmuş ve Analitik Hiyerarşi modeli ile uygun personel seçimi için 3 aday belirlenmiştir.

Chen ve Cheng'in (2005), bilişim sistemlerinde personel seçmeye yönelik bir çalışma yapmışlardır. Bu çalışmada, bilişim sektöründe faaliyet gösteren bir firmanın proje yöneticisi seçme işlemi uzmanlar tarafından belirlenen kriterler, bulanık sayılar ile değerlendirilmiştir.

Karsak (2001), personel seçme probleminin çözümü için çok kriterli karar verme yöntemlerinden TOPSIS (technique for order preference by similarity to ideal solution) ve bulanık mantığı birlikte kullanmıştır.

Herrera ve diğerleri (2001) dilsel genetik algoritmalar kullanarak personel seçim problemine çözüm aramışlardır. Bahsi geçen çalışmalardan da anlaşıldığı üzere sosyal alanda yapılan araştırmalarda öne çıkan araştırma alanları uygun personel seçimi üzerine yoğunlaşmaktadır.

Eğitim alanında bulanık mantık ile yapılan çalışmalarda da durum diğer sosyal alanlarla benzerlik göstermektedir. Öğrenci seçme ve sınıflama üzerine yapılan araştırmalar yoğunluktadır. Bunun yanında işbirlikli öğrenme ve eğitimde hipermedya uygulamalarında bulanık mantıkla yapılan çalışmalar ve öğrenci başarısızlıklarının bulanık mantık ile yorumlandığı araştırmalar da mevcuttur.

Kaptanoğlu ve Özok (2006)“Akademik performans değerlendirmesi için bir bulanık model" isimli çalışmalarında, akademisyenlerin akademik performanslarını bulanık analitik hiyerarşi prosesi modelinin temel alındığı çalışmada üç ayrı bulanık sıralama yöntemi kullanarak belirlemiş ve bu yöntemlerin sonuçlarını tartışmışlardır. Çalışmalarının sonucu olarak, akademik performans değerlendirme probleminin birçok ölçütlü bulanık karar verme problemi olarak çözülebileceği sonucuna ulaşmışlardır.

Ertuğrul (2006) “Akademik performans değerlendirmede bulanık mantık yaklaşımı” isimli çalışmasında Pamukkale Üniversitesinin, bir fakültesinde dört bölümde çalışan öğretim üyelerinin performansının değerlendirilmesinde bulanık mantık kullanılmış, öğretim üyelerinin verilerinin sözel olarak ifade edilen ölçütleri sayısallaştırarak değerlendirilebildiği sonucuna ulaşılmıştır. Performans yorumlamasının doğru yapılması açısından, her bölümün kendine ait bulanık mantık tablosuna bakılması gereği ortaya çıkmıştır.

Bakanay (2008), "Mikro öğretimde performansın bulanık mantık yöntemiyle değerlendirilmesi" adlı yüksek lisans tezinde öğretmen adaylarının mikro öğretimdeki performanslarını değerlendirmiştir. Öğretmen adaylarının "Öğretmenlik uygulaması" dersindeki başarıları bulanık mantık yöntemiyle değerlendirilmesi yapılmıştır. 
Kazu ve Özdemir (2009)'da “Öğrencilerin bireysel özelliklerinin yapay zekâ ile belirlenmesi (Bulanık Mantık Örneği)" isimli çalışmalarında öğrencilerin bireysel farklılıklarının dikkate alınmasında yapay zeka teknolojilerinin kullanılabilirliğini araştırmışlar ve sonuç olarak yapay zeka teknolojilerinin eğitim organizasyonlarını da etkilediği ve ölçeklerin değerlendirilmesinde de kullanılabilir olduğunu savunmaktadırlar. Çoklu Zekâ Kuramı veya Öğrenme Stillerine Dayalı eğitim/öğretim uygulamaları için Öğrencilerin Bireysel Özelliklerinin Yapay Zekâ ile Belirlenmesini Bulanık Mantık Örneği ile açıklayan bir çalışma yapmışlardır.

Ar1 ve Vatansever (2009)'da öğrencilerin mesleki yeteneklerinin tespit edilip, kendilerine uygun alanlarda eğitim görmelerini sağlamak amaçlı bulanık mantık tabanlı mesleki yönlendirme çalışmasını yapmışlardır. "Bulanık mantık tabanlı mesleki yönlendirme" isimli çalışmalarında lise öğrencilerinin mesleğe yönlendirilmesinde; onların geçmiş eğitim başarıları ve öğretmen görüşleri kullanılarak mesleki ilgi ve yeteneklerinin tespiti, bulanık mantık kurallarıyla gerçekleştirilmiş ve bu tür yaklaşımlarla daha etkin ve doğru sonuçlara ulaşılabileceği sonucuna ulaşmışlardır.

Uysal (2010) "Öğrenme stillerinin bulanık mantıkla modellenmesi” isimli çalışmasında Felder ve Soloman Öğrenme Stilleri (Index of Learning Styles) Bulanık Mantıkla modellenerek öğretim ortamlarıyla ilgili belirsizlikler giderilmeye çalışılmıştır.

Dülger (2013)'de "Hiyerarşik uyarlanabilir ağ tabanlı bulanık çıkarım sistemi kullanılarak matematik 1 dersi başarı tahmini” isimli çalışmasında mühendislik öğrencilerinin matematik 1 dersindeki başarılarını önceden tahmin etmeye yönelik yaptığı çalışmasında \%77,77 ve \% $\% 8,47$ genel tahmin oranına sahip iki tane iyi sonuç elde etmiştir.

Çiçekli ve Karaçizmeli (2013),öğrencilerin genel not ortalaması derse devam etme, sosyal sorumluluk projelerine katılım ve bilgisayar kullanma becerisi gibi becerileri dikkate alarak başarılı öğrenci belirlemesinde bulanık analitik hiyerarşi süreci yaklaşımını kullanmışlardır.

Yııdız, Bal ve Gülseçen (2013) uzaktan eğitim öğrencilerinin akademik başarılarını bulanık mantık ile değerlendirmişlerdir. 218 öğrencinin temel bilgisayar dersindeki başarılarını değerlendirdikleri çalışmalarında bulanık mantıkla yapılan değerlendirmenin daha nitelikli bir değerlendirme sunduğuna dair bulgulara ulaşmışlardır.

Güner ve Çomak (2014), "Lise öğrencilerinin matematik dersine yönelik tutumlarının bulanık mantık yöntemi ile incelenmesi" isimli çalışmasında matematik dersi tutum ölçeği geliştirilmiş ve 30170 lise öğrencisine Bulanık Mantık yöntemi uygulanarak gerçekleştirilmiştir. Yapılan hesaplamalar sonucunda Türkiye'de eğitim gören lise öğrencilerinin matematik dersine yönelik tutumlarının öğrencilerin cinsiyeti, okumakta oldukları lise türü ve yaşadıkları coğrafi bölgelere göre nasıl değiştiği daha önceki proje sonuçları ile karşılaştırılmıştır.

Hadjileontiadou ve Hadjileontiadis (2003) işbirlikçi ve metabilişsel veriler üzerine yoğunlaşan araştırmada katılımcıların işbirliği becerileri ve kaliteye olan inançları ile ilgili amprik verilerin kolay analiz edilmesi için bulanık mantık kullanmışlardır.

Kavcic ve diğerleri (2003) çalışmalarında, yetkinliğe dayalı öğretim tasarımı sistemi ve ders içeriğinin kişiselleştirilmesini bulanık mantık yöntemi ile sunuyor. Her bir yeterlilik basamağı için zorluk seviyesi ve ön koşullarını takip edip belirlemeyi bulanık mantık kullanarak yapmışlardır. Dolayısı ile tavsiye seviyesine ilişkin net kategoriler verilmektedir.

Hadjileontiadou, Nikolaidou, Hadjileontiadis, ve Balafoutas (2003) çalışmalarında bulanık mantık temelli bir uzman sistem sunmuşlardır. İşbirliği / Yansıma-Bulanık Çıkarım Sistemi ile deneysel kullanımından elde edilen sonuçlara göre önerilen modelin işbirlikçi etkinliğin geliştirilmesine tıp, çevre mühendisliği, hukuk ve müzik eğitimi gibi diğer işbirlikli öğrenme bağlamlarına aktarılabilirliğine önemli ölçüde katkıda bulunma potansiyelini kanıtlamışlardır. 
Gravani, Hadjileontiadou, Nikolaidou ve Hadjileontiadis (2007) çalışmalarında sayg1, işbirliği, karşılıklı güven, destek olma, açıklık gibi parametreden yola çıkarak mesleki öğrenmenin sayılan bu bileşenlerden etkilenme durumlarını belirlemeye çalışmışlardır. Bu yazıda önerilen kantitatif, bulanık mantık temelli model Yunanistan'daki bir hizmet içi eğitim programından alınmış bir dizi temsil verisi arasındaki ilişkileri analiz etmiştir. Bulanık mantık ile önerilen modellemenin mesleki öğrenmede klasik niteliksel yaklaşımla istatistiksel olarak anlamlı farklı eğilimleri ortaya çıkardığını ve bu eğilimleri niceliksel olarak ortaya koyduğu bulgusuna ulaşmışlardır.

Hwang, Huang ve Tseng (2004) de eğitim web sitelerini değerlendirmek için yaptıkları araştırmalarında bulanık mantığında içinde bulunduğu 3 farklı yöntemle bilgisayar destekli bir web sitesi değerlendirme sistemi olan Eğitimsel Web Sitesi Değerlendiricisini geliştirmişlerdir.

Dweiriand Kablan (2006) çalışmalarında proje maliyeti, proje süresi ve proje kalitesi kriterlerini dikkate alarak bulanık mantık tabanlı bir karar verme sistemi için MATLAB yazılımı kullanılarak tasarlanmış bir yönteme odaklanmıştır. Bu araştırmada önerilen metodoloji ve prosedür, proje yönetimi organizasyonları tarafından kolayca uygulanabilir olarak nitelendirilmiştir.

\section{4. İki Uygulamaya Dair Detaylar}

Sosyal araştırmalarda çoğunlukla bireylere yönelik bazı bilgilerin bulunduğu veri kümelerinin bulanık sisteme dâhil edilebilmesi gerekmektedir. Bu veri kümeleri bir anketin sonuçları, öğrencilerin öğrenme stilleri, sınav not bilgileri, duyuşsal verilere dair anket bilgileri olabilmektedir.

Çalışmaların genelinde bulanık mantığın daha hassas sonuçlar vermesi özelliğinin üzerinde durulduğu göze çarpmaktadır. Kesin olmayan ve yaklaşık bilgilerin kullanılmasına imkân tanımakta ve kesin olmayan ve belirsiz birçok problemin matematiksel olarak formüle edilmesini sağladığı için tercih edildiğinden bahsedilmektedir. Bu bölümde iki araştırmaya dair daha detaylı bilgiler örnek teşkil etmesi amacı ile verilmiştir.

Bulanık mantık ile öğrencilerin matematiğe yönelik tutumlarının araştırıldığı bir araştırmada (Güner ve Çomak ,2014). Veri kümesini oluşturan anket çalışması, 35 adet sorudan oluşmuş, bu sorulardan rastgele sırada 10 tanesi birinci faktörü, 10 tanesi ikinci faktörü, 8 tanesi üçüncü faktörü ve 7 tanesi de dördüncü faktörü oluşturacak şekilde araştırmacılar tarafından seçilmiş̧tir. Bu veri kümesine uygun olarak bulanık sistem dört giriş ve bir çıkış birimi içermiştir. Çalışmada dört çeşit bulanık sistem uygulaması gerçekleştirilmiştir. İlki 30170 öğrenci anket verisi üzerinde öğrencilerin matematik dersine yönelik tutumlarını hesaplayan sistem. İkincisi, tüm verilerin cinsiyete göre ayrılıp kız ve erkek öğrencilerin matematik dersine yönelik tutumlarının bulunması ile ilgili sistem. Üçüncüsü, öğrencilerin eğitim gördükleri lise türüne göre, her bir lise türünün bağımsız olarak ele alınıp matematik tutumlarının hesaplandığı sistem. Sonuncusu ise öğrenci verilerinin coğrafi bölgelere göre ayrılıp matematik tutumlarının bağımsız olarak hesaplandığı uygulama olarak araştırmada belirlenmiştir. Her bulanık sistem uygulaması için üyelik fonksiyonu seçilmelidir. Araştırmada üç çeşit üyelik fonksiyonu grubuyla sistem uygulaması çalıştırılmıştır. Bu üyelik fonksiyonları; üçgen, yamuk ve Gauss tipi fonksiyonlar olarak seçilmiştir. Kural tabanları yazılmış ve üç bulanık mantık metodu kullanılarak çalışma yapılmıştır. Araştırmada kullanılan verilerin bulanıklaştırılması amacıyla üç çeşit alternatif üyelik fonksiyonu (üçgen tipi, yamuk tipi ve Gauss tipi) kullanılmıştır. Bulanıklaştırma birimi dışındaki bulanık sistem birimleri ise birbiriyle aynıdır. Kural tabanı 352 adet kuraldan oluşmuştur. Durulaştırma biriminde ise alan merkezi (centroid) yöntemi kullanılmıştır. Yapılan hesaplamalar sonucunda Türkiye'de eğitim gören lise öğrencilerinin matematik dersine yönelik tutumlarının öğrencilerin cinsiyeti, okumakta oldukları lise türü ve yaşadıkları coğrafi bölgelere göre nasıl değiştiği daha önceki proje sonuçları ile karşılaştırılmıştır. Her üç bulanık mantık üyelik fonksiyonu ile yapılan hesaplamalar sonucunda 
Türkiye genelinde lise öğrencilerinin matematik dersine yönelik tutumlarının orta düzeyde olduğu bulunmuştur. Aynı verilere yönelik klasik istatistik yöntemleri ile elde edilen ortalama 2,7432 olarak bulunurken, Üçgen, yamuk ve Gauss bulanık sistem uygulamalarında öğrencilerin tutum ortalamaları sırası ile 2,8965, 2,9012 ve 2,8704 olarak hesaplanmıştır. İncelediğimiz bu çalışmada yazarlar matematik dersine karşı tutumu belirlemeye yönelik daha önce geliştirilmiş bir ölçme aracının bulanık mantık kullanılarak hassasiyetinin artırılmasını amaçlamışlardır.

Bir diğer uygulama Bulanık AHP ile personel seçimi. (Özgörmüş, Mutlu ve Güner, 2005). Uygulamada, gıda sektöründe faaliyet gösteren bir işletmenin "tedarik planlama mühendisi seçme" problemi ele alınmış, işletmenin insan kaynakları birimi tarafından yapılan iş analizleri sonucunda hazırlanan iş tanımlarından yola çıkılarak işin gerektirdiği özellikler belirlenmiştir. $\mathrm{Bu}$ özellikler problemdeki seçme kriterlerinin temelini oluşturmuştur. Karar vericilerin belirlediği yedi ana kriterden fiziksel özellikler ve yetkinlikler ayrıca alt kriterlere de sahiptir. $\mathrm{Bu}$ kriterlerden ilki olan fiziksel görünüş; özgeçmişlerin incelenmesinden sonra uygun görülen ve mülakata davet edilen adayların gerek karar vericide bıraktığı ilk intiba, gerekse sorulara verdiği cevaplar dikkate alınarak değerlendirilmiştir. İkinci ve en önemli ana kriter olan eğitim; işin gerektirdiği teknik ve teorik bilgiye sahip olup olmadığını, mezun olunan bölüm ve üniversite dikkate alınarak değerlendirilmiştir. Tedarik planlaması yapılırken yurtdışından tedarikçi firmalarla bağlantıya geçilmesi söz konusu olduğundan ve günümüz koşullarında temel istihdam koşulu olan yabancı dil bilgisi de değerlendirme kriterleri arasına alınmış. Yabancı dil seviye tespit sınavlarından (TOEFL, KPDS vb.) aldığı puanlar veya işletmenin dil sınavından alınan puanla ölçülmektedir. Diğer önemli bir kriter olan bilgisayar bilgisi, Microsoft Office paket programlarına hakimiyetin yanı sıra işletme koşullarına göre yazılım geliştirmeyi sağlayan güncel programlama dillerinden birini bilmesi ile değerlendirilmektedir. Deneyim, ise adayın o iş için ne kadar kalifiye olduğu hakkında bilgi veren bir kriterdir. Son kriter olan referans ise, kişinin daha önce çalıştığı kurum yada önceden kendisini tanıyan insanların verdiği bilgiler doğrultusunda daha iyi tanınmasını sağlamaktadır.

Ana kriterler, alt kriterler ve seçenekleri değerlendirirken uzmanlar dilsel değişkenleri kullanmışlardır. Yapılan iş analizleri ve iş tanımları doğrultusunda işin nitelik ve nicelikleri belirlenmiş, işe gerek internet yoluyla, gerekse bireysel başvurular dikkate alınarak değerlendirilen adaylardan ancak 3 adayın bu işe en uygun sayılabilecek niteliklere sahip olduğu görüşüne varılmıştır. Çalışmada, bu 3 adayın hangisinin en uygun olduğuna ise AHP ve Bulanık Mantık birlikte kullanılarak gerçek hayatta kullanılan dilsel tanımlardan faydalanarak karar verilmiştir. Ayrıca adayların değerlendirilmesinde kullanılan ana kriterler arasında eğitim ve deneyimin çok önemli olduğu sonucuna varılmıştır. Bu çalışma ile bulanık AHP'nin personel seçimine sayısal bir çözüm getirerek, karar vermede gözle görülebilir bir kolaylık ve hassaslık sağladığı sonucuna ulaşılmıştır.

\section{Tartışma ve Öneriler}

Klasik küme teorisinde bir eleman o kümenin ya elemanıdır ya da değildir. Kısmi üyelik olmaz. Doğal olarak bu mantığın hiçbir esnekliği yoktur. Gerçek dünyada ise sınırlar, bu kadar keskin değildir. Günümüzde karar verme problemlerinin çoğu tam ve kesin olmayan bilgilerin kullanılmasını gerektirmesine rağmen, birçok karar verme ve problem çözme aracı nicel verilerin kullanılması ile çözüme gitmektedir. Bulanık küme teorisi karar verme sürecinde kesin olmayan ve yaklaşık bilgilerin kullanılmasına imkân tanımakta ve kesin olmayan ve belirsiz birçok problemin matematiksel olarak formüle edilmesini sağlamaktadır.

Çalışmada sosyal alanlar özelliklede eğitim alanında bulanık mantık ile yapılmış çalışmalar incelenmiştir. Çalışmalarda öne çıkan sonuçların en başında, çok ölçüte bağlı olan akademik performansın değerlendirmesinin bir "çok ölçütlü bulanık karar verme" problemi olarak ele alınıp çözülebileceği durumudur. Akademik performansın doğru olarak değerlendirilmesi ve 
kalitenin belirlenmesi açısından esnek yapısından dolayı bulanık mantık modeli tercih edilen bir model olduğu vurgusu yapılmıştır.

Çalışmaların sonuçları akademik başarının belirlenmesinde sadece belirli nicel değerlere odaklanmak yerine, çoklu kriterlere yönelmenin daha esnek ve gerçekçi bir sıralamayı veya sınıflamayı beraberinde getirdiğini ve bulanık mantıkla yapılan değerlendirmenin diğer klasik değerlendirme yöntemlerine göre daha başarılı sonuçlar verdiğini göstermektedir.

Eğitim alanı dışında sosyal alanlarda yapılan birkaç çalışmaya da araştırmada yer verilmiştir. Bu çalışmalarda personel seçiminde kullanılan bulanık mantık modelinin karar verme süreçlerinde etkili bir model olduğu sonucuna ulaşılmıştır. Benzer şekilde eğitim alanında lisansüstü eğitime öğrenci alımlarının yapıldığı veya genel yetenek ile öğrenci alımı yapan kurumlarda iyi bir karar sürecini yönetmek için bulanık mantıktan yararlanılabilir ve bu konuda çalışmalar yapılabilir. Yapay sinir ağları ile lisansüstü eğitime girebilmeye yönelik başarı tahmini yapılan çalışmalar vardır (Lee,2010; Bahadır,2016a ve Bahadır 2016b) ancak lisansüstü eğitim ve bulanık mantık ile yapılan herhangi bir çalışmaya rastlanmamıştır. Bu alanda çalışmalar yapılabilir.

Bulanık mantıkla yapılacak olan çalışmalara öğrencilerin duyuşsal özelliklerinin de katıldığı çalışmaların artması öğrenci başarısını yorumlamamızda eğitimcilerin daha nitelikli karar vermelerini sağlayacaktır.

Literatürde Likert tipi ölçeklerin bulanık mantıkla değerlendirildiği çalışmalara rastlamak mümkündür Li(2013)'de likert ölçekleri bulanık mantıkla yorumlamıştır. Tsaura, Changb ve Yena (2002)'de havayollarının servis kalitesini belirlemek amaçlı bulanık tabanlı değerlendirme kullanmışlardır. Bulanık likert değerlendirme ile yorumlamanın üstünlüklerine çalışmalarında değinmişlerdir. Aynı şekilde eğitim alanında da çeşitli duyuşsal öğelerin belirlenmesi için kullanılan likert tipi ölçeklerin değerlendirilmesi bulanık mantıkla yapılabilir ve daha nitelikli sonuçlara ulaşılabilir.

Araştırmalarda bulanık mantık yaklaşımının gerçek, karmaşık verilere özgü bilgileri yakalama yönündeki avantajlarını her araştırmada vurgulanmaktadır mesleki öğrenmenin pek çok bileşeni göz önüne alındığında mesleki öğrenme ile ilgili daha buluşsal fikirler ve araştırma yönergeleri ortaya çıkarmakta bu yöntem kullanılabilir.

Ayrıca eğitim alanındaki projelerin değerlendirilmesinde proje yöneticilerinin ve proje organizasyonlarının, proje yönetimi iç hedeflerine ulaşma düzeyini gösteren bir gösterge olarak görev yapabilir ve proje ekiplerinin performans değerlendirmesinde yardımcı olabilir.

Bulanık mantıkta keskin çizgiler yoktur ki bu durum gerçek dünyaya daha uygundur yani daha gerçekçidir. Yapılan çalışmalarda akademik başarının değerlendirilmesinde bulanık mantık yaklaşımı ile sözel olarak ifade edilen ölçütleri sayısallaştırarak değerlendirilebilmektedir. Ayrıca çalışmalarda bulanık mantığı öne çıkaran nokta performans değerlendirmeye bulanık mantık prensiplerinin uygulanmasıyla birlikte, var olan sistem için istenen esneklik sağlanabilmesidir. Sonuç olarak bulanık mantık yöntemi ile akademik başarının bağlı olduğu çeşitli bileşenler birlikte değerlendirilip öğrenci başarısına yönelik daha tutarlı yorumlar yapılabilir. Eğitime yönelik diğer çalışmalarda da etkin bir şekilde kullanılabilir. 


\section{Kaynaklar}

Altaş, İ. H. and Sharaf, A. M. (1992). "A fuzzy logic power tracking controller for a photo voltaic energy conversion scheme” Electric Power Systems Research Journal, (25), 3, 227238.

Akandere, M., Özyalvaç, N. T. \& Duman, S. (2010). “Ortaöğretim öğrencilerinin beden eğitimi dersine yönelik tutumları ile akademik basari motivasyonlarının incelenmesi (Konya Anadolu Lisesi Örneği)". Selçuk Üniversitesi Sosyal Bilimler Enstitüsü Dergisi, (24), 1-10.

Akandere M, Baştuğ G, Güler DE (2009). “Orta öğretim kurumlarında spora katılımın çocuğun ahlaki gelişimine etkisi”. Niğde Üniversitesi Beden Ĕ̆itimi ve Spor Bilimleri Dergisi, 3(1): 59-68.

Akiyama, T. \& Tsuboi, H. (1996,). "Description of route choice behaviour by multi-stage fuzzy reasoning". In High ways to the Next Century Conference, Hong Kong.

Ar1, E. \& Vatansever, F.(2009). "Bulanık Mantık Tabanlı Mesleki Yönlendirme”. 5. Uluslararası Illeri Teknolojiler Sempozyumu (IATS’09), 13-15 Mayıs 2009, Karabük

Aslam, M.Z. \& Khan, A.R. (2011) “A Proposed Decision Support System/Expert System for Guiding Fresh Students in Selecting a Faculty in Gomal University”, Pakistan. Ind Eng Letters, 1(4), 33-40. Available under http://www.iiste.org. Accessed on November 13, 2013.

Aydın, N. (2015) http://www.elektrikport.com/teknik-kutuphane/bulanik-mantik-nasil-calisir1-bolum/14849\# erişim tarihi 12/05/2016

Aydın, T. (2015). Bulanık mantık sınıflandırmadan yararlanarak kablo malzemesi seçimi (Doctoral dissertation, Fen Bilimleri Enstitüsü).

Bakanay, D.(2009). Mikro öğretimde performansın bulanık mantık yöntemiyle değerlendirilmesi. MScThesis (in Turkish), Marmara University

Bahadir, E. (2016 a). "Prediction of Prospective Mathematics Teachers' Academic Success in Entering Graduate Education by Using Back-propagation Neural Network". Journal of Education and Training Studies, 4(5), 113-122.

Bahadir, E. (2016 b). "Using Neural Network and Logistic Regression Analysis to Predict Prospective Mathematics Teachers' Academic Success upon Entering Graduate Education". Kuram ve Uygulamada Eğitim Bilimleri. Advance online publication. doi: 10.12738/estp.2016.3.0214

Bendjebar, S., Lafifi, Y., \& Seridi, H. (2016). "Modeling and Evaluating Tutors' Function using Data Mining and Fuzzy Logic Techniques”. International Journal of Web-Based Learning and Teaching Technologies (IJWLTT), 11(2), 39-60.

Bukata, B. B., \& Li, Y. (2012). "A novel model-free prediction of power quality problems via DSTATCOM". In Automation and Computing (ICAC), 2012 18th International Conference on (pp. 1-6). IEEE.

Chen, L. S.,\&Cheng, C. H. (2005). "Selecting IS personnel use fuzzy GDSS based on metric distance method". European Journal of Operational Research, 160(3), 803-820.

Cox, R.H. (1990) Sport Psychology. Concepts and Applications, Second Edition.

Çiçekli, U. G.\&Karaçizmeli, A. (2013). "Bulanık analitik hiyerarşi süreci ile başarılı öğrenci seçimi: Ege Üniversitesi İktisadi ve İdari Bilimler Fakültesi Örneği”. Ege Stratejik Araştırmalar Dergisi, 4(1), 71-94. 
Dağdeviren, M. (2007). "Bulanık Analitik Hiyerarşi Prosesi İle Personel Seçimi Ve Bir Uygulama”. Gazi Üniversitesi Mühendislik-Mimarlık Fakültesi Dergisi, 22(4), 791-799.

Diaz, A. R. (1989). "A strategy foroptimal design of hierarchical systems using fuzzy sets". In The 1989 NSF Engineering Design Research Conference (pp. 537-547).

Dülger, Ö.( 2014) "Hiyerarşik Uyarlanabilir A ğ Tabanlı Bulanık Çıkarım Sistemi Kullanılarak Matematik 1 Dersi Başarı Tahmini”, Pamukkale Üniversitesi Mühendislik Bilimleri Dergisi, 20 (5), 166-173

Dweiri, F. T.,\&Kablan, M. M. (2006). "Using fuzzy decision making for the evaluation of the Project management internal efficiency”. Decision Support Systems, 42(2), 712-726.

Ertuğrul, İ. (2006). "Akademik Performans Değerlendirmede Bulanık Mantık Yaklaşımı". Atatürk Üniversitesi İktisadi ve İdari Bilimler Dergisi, 20(1).

Fourali, C. (1997). "Using fuzzy logic in educational measurement: thecase of portfolio assessment”. Evaluation \&Research in Education, 11(3), 129-148.

Gravani, M. N.,Hadjileontiadou, S. J., Nikolaidou, G. N., \&Hadjileontiadis, L. J. (2007). "Professional learning: A fuzzylogic-based modeling approach". Learning andInstruction, 17(2), 235-252.

Güner, N., \& Çomak, E. (2014). "Lise Öğrencilerinin Matematik Dersine Yönelik Tutumlarının Bulanık Mantık Yöntemi İle İncelenmesi Investıgatıng Mathematıcs Attıtude For High School Students By Using Fuzzy Logic Method". Pamukkale University Journal of Engineering Sciences, 20(5), 189-196.

Hadjileontiadou, S. J.,Nikolaidou, G. N., Hadjileontiadis, L. J., \&Balafoutas, G. N. (2004). “On enhancing on-line collaboration using fuzzy logic modeling". Journal of Educational Technology \& Society, 7(2), 68-81.

Herrera, F., Lopez, E., Mendana, C., Rodriguez, A. M., 2001, “A LinguisticDecision Model forPersonnel Management Solvedwith A Linguistic Biobjective Genetic Algorithm", Fuzzy Sets and Systems, 118, 47-64.

Kaptanoğlu, D., \& Özok, A. F. (2010). "Akademik performans değerlendirmesi için bir bulanık model". ITÜ DERGISI/d, 5(1), 193-204.

Karsak, E. E. (2001), "Personnel Selection Using a Fuzzy MCDM Approach Based on Idealand Anti-Ideal Solutions. Multiple Criteria DecisionMaking in the New Millennium", Lecture Notes in Economics and Mathematical Systems, Springer, 507, 393-402.

Kazu, İ. Y.,\& Özdemir, O. (2009). "Öğrencilerin bireysel özelliklerinin yapay zeka ile belirlenmesi (Bulanık mantık örneği)". In Akademik Bilişim 2009 Konferansı, 11-13 Şubat 2009 (pp. 457-466). Harran Üniversitesi, Şanlıurfa.

Kavcic, A.,Pedraza-Jiménez, R., Molina-Bulla, H., Valverde-Albacete, F. J., Cid-Sueiro, J., \& Navia-Vázquez, A. (2003). "Student modeling based on fuzzy inference mechanisms". In EUROCON 2003. Computer as a Tool. The IEEE Region 8 (Vol. 2, pp. 379-383). IEEE.

Kazancoglu, Y., \& Aksoy, M. (2011). "A fuzzy logic-based quality function deployment for selection of e-learning provider". TOJET: The Turkish Online Journal of Educational Technology, 10(4). 80-98.

Kılıç, E.\& Karadeniz, Ş. (2004). "Cinsiyet ve Öğrenme Stilinin Gezinme Stratejisi veBaşarıya Etkisi”. Gazi Eğitim Fakültesi Dergisi, 24(3), 129-146. 
Li, K. K.,Lai, L. L.\& David, A. K. (2000). "Standalone intelligent digital distancerelay”. Power Systems, IEEE Transactions on, 15(1), 137-142.

Liu, C. C., Pierce, D.\&Song, H. (1997). "Intelligent system applications to power systems". Computer Applications in Power, IEEE, 10(4), 21-22.

Lo H.\&Lam W.S.P.(1997). “A Modified Multinomial Logit Model of Route Choicefor Drivers Using the Transportation Information System”, 295-299s.,Proceedings of 9th Mini-EURO Conference,

Onat, N. C., Gumus, S., Kucukvar, M., \& Tatari, O. (2016). "Application of the TOPSIS and intuitionistic fuzzy set approaches for ranking the life cycle sustainability performance of alternative vehicle Technologies". Sustainable Production and Consumption, 6, 12-25.

Özgörmüş, E., Mutlu, Ö., \& Güner, H. (2005). "Bulanık AHP ile personel seçimi". acikerisim.ticaret.edu.tr adresinden 20.12.2016 tarihinde indirilmiştir.

Peker, M. \& Mirasyedioğlu, S. (2003). "Lise 2. Sınıf öğrencilerinin matematik dersine". Pamukkale Üniversitesi Eğitim Fakültesi Dergisi,14(14), 157-166.

Rollnick, S. (2008). "Talking about behaviour change: Is guiding more effective than directing?". South African Family Practice, 50(2), 52-52.

Saral, Ş. (1993). "Özel Trabzon Ata Koleji öğrencilerinin uyum düzeyleri ile akademik başarıları arasındaki ilişkinin araştırılması”. Yayınlanmamış Yüksek Lisans Tezi, Karadeniz Teknik Üniversitesi, Trabzon.

Sattarov, R. (2015). Kalite fonksiyon yayılımında bulanık mantık yaklaşımı: Beyaz eşya sektöründe bir uygulama (Doctoral dissertation, İstanbul Teknik Üniversitesi, Fen Bilimleri Enstitüsü).

Semerci, Ç. (2004). "The Influence of Fuzzy Logic Theory on Students' Achievement”. TOJET: The Turkish Online Journal of Educational Technology, 3(2), 56-64.

Singh, B., \& Arya, S. R. (2014). "Back-propagation control algorithm for power quality improvement using DSTATCOM". IEEE transactions on industrial electronics, 61(3), 1204-1212.

Smithson, M. J. (1987). "Fuzzy set analysis forthebehavioralandsocialsciences (RecentResearch in Psychology)". New York: Springer-Verlag.

Sobecki J. (2012) "Comparison of nature inspired algorithms applied in student courses recommendation. In: Computational Collective Intelligence". Technologies and Applications, 278-287. Springer Berlin Heidelberg.

Sunter, Z., Altun, H., \& Sunter, S. (2015). "A New Approach for Harmonic Elimination in Single-Pulse Modulated Single-Phase Inverter Drive System". Journal of the Faculty of Engineering and Architecture of Gazi University, 30(2), 237-247.

Şen, A. İ.\& Koca, S. A. (2005). "Ortaöğretim öğrencilerinin matematik ve fen dersine yönelik tutumları ve nedenleri”. Eğitim Araştırmaları, 18, 236-252.

Tsaura,S. H. , Changb, T.Y. \&Yena, C., H.(2002). "Theevaluation of airline service qualitybyfuzzy MCDM", Tourism Management 23 (2002) 107-115

Temurtas, F.(2000). "Kimyasal Sensör Dizilerinde Yapay Sinir Agları ve BulanıkMantık Uygulamaları: Gazların Sinıflandırılması ve Gaz Konsantrasyonlarının Belirlenmesi", Doktora Tezi, Sakarya Üniversitesi, Sakarya. 
Terzi, Ü. (2004). "Taguchi Yöntemi ve Bulanık Mantık Kullanılarak Çok Yanıtlı KaliteKarakteristiklerinin eş zamanlı Eniyilenmesi”, Yüksek Lisans Tezi, Kocaeli Üniversitesi, Kocaeli.

Uysal, M. P. (2010). “Öğrenme stillerinin bulanık mantıkla modellenmesi”. In 4th International Computer \& Instructional Technologies Symposium (pp. 1040-1045). Selçuk University Konya, Turkey.

Voskoglou, M. G. (2013). "Fuzzy Logic as a tool for assessing students' knowledge and skills". Education Sciences, 3(2), 208-221.

Yıldız, O., Bal, A.\&Gülseçen, S. (2013). "Improved fuzzy modelling to predict the academic performance of distance education students". The International Review of Research in Open and Distributed Learning, 14(5).

Yuan,B.\&Kor,J.G.(1994). Fuzzy Sets And Fuzzy Logic Theory And Aplications ,New York. 